04

\title{
Килогерцевый плазменный карандаш
}

\author{
(C) Tamer Akan ${ }^{1}$, Ece Şahin ${ }^{2}$ \\ ${ }^{1}$ Eskisehir Osmangazi University, Faculty of Science and Letters, Department of Physics, Eskisehir, Turkey \\ ${ }^{2}$ Graduate School of Sciences, Eskisehir Osmangazi University, Eskisehir, Turkey \\ E-mail: akan@ogu.edu.tr
}

Поступило в Редакцию 15 ноября 2021 г.

В окончательной редакции 15 ноября 2021 г.

Принято к публикации 10 января 2022 г.

Недавно было опубликовано несколько исследований, посвященных различным устройствам, генерирующим струи холодной плазмы атмосферного давления. Одно из таких устройств, о разработке которого неоднократно сообщалось в литературе, - импульсный источник плазмы "плазменный карандаш". Этот прибор может генерировать факел холодной плазмы длиной в несколько сантиметров с помощью импульсного высоковольтного источника постоянного тока. В приборе, являющемся объектом данного исследования, на электроды той же конфигурации, что и в плазменном карандаше, вместо импульсного напряжения постоянного тока подавалось напряжение переменного тока килогерцевого диапазона $(18 \mathrm{kV}$, $15 \mathrm{kHz}$ ). При этом в воздухе создавалась струя плазмы длиной $2-3 \mathrm{~cm}$ на основе газообразного гелия. Этот новый генератор плазменной струи получил название „килогерцевый плазменный карандаш“. Температура струи, вырабатываемой килогерцевым плазменным карандашом, не превышает комнатной температуры. Нами исследовался спектр оптического излучения струи килогерцевого плазменного карандаша, а также изменение длины струи в зависимости от расхода газа. В отличие от плазменного карандаша килогерцевый плазменный карандаш генерирует струю в двух различных режимах: нитевидном и диффузном. Кроме того, доля излучения его струи, приходящаяся на УФ-диапазон, более значительна. Предварительные результаты показали, что и динамические характеристики килогерцевого плазменного карандаша отличаются от соответствующих характеристик плазменного карандаша.

Ключевые слова: струя холодной плазмы атмосферного давления, килогерцевый диапазон, плазменный карандаш, спектр излучения.

DOI: 10.21883/PJTF.2022.07.52283.19078

Плазменные струи атмосферного давления без использования дуги обратной полярности называются в литературе струями плазмы в локальном термодинамическом равновесии, неравновесными плазменными струями, нетермическими плазменными струями, струями холодной плазмы или струями низкотемпературной плазмы. Широкий обзор недавно разработанных методов генерации указанных неравновесных плазменных струй был представлен в 2007 г. в работе [1]. Одна из основных характерных особенностей струй холодной плазмы атмосферного давления (atmospheric pressure cold plasma jets, AРСРЈ) состоит в том, что плазма, создаваемая внутри прибора (в области генерации плазмы), выпускается из него во внешнюю среду или на открытый воздух в виде факела или струи. АРСРЈ представляют интерес благодаря их способности доставлять на значительные расстояния от области разряда массивы активных частиц большой плотности при низкой температуре газа. Генераторы струй АРСРЈ привлекли к себе большое внимание благодаря сочетанию простоты конструкции, низкой стоимости и широкого спектра предоставляемых ими возможностей очистки и модификации поверхностей при обработке металлов и полимеров, а также биомедицинских приложений [2]. Поскольку генераторы струй АРСРЈ работают при температурах, незначительно превышающих комнатную, они обладают огромным потенциалом в широком диапазоне биомедицинских приложений, таких как стерилизация и бактериальная инактивация, стоматология, заживление ран, онкология (обработка злокачественных клеток) и генетика (состав крови и ДНК). Были также проведены и опубликованы обширные исследования в отношении возможности применения АРСРЈ для обработки пищевых продуктов [3], зерна [4], текстильных изделий [5] и воды [6].

Существует ряд различных методов генерации АРСРЈ: микроволновый разряд, радиочастотный разряд, диэлектрический барьерный разряд и разряд постоянного тока. Хотя классификация источников АРСРЈ проводится в соответствии с возрастанием частотного диапазона источников тока, используемых для их инициации и поддержки, очень важным конструкционным параметром, влияющим на генерацию плазменных струй, является также конфигурация электродов [7]. Исследования, результаты которых изложены в $[8,9]$, позволили разработать импульсное устройство „Плазменный карандаш“, работающее при атмосферном давлении и комнатной температуре. Плазменный карандаш производит плазменную струю атмосферного давления, питаемую короткими импульсами высокого напряжения, которая может выпускаться в воздух помещения в виде плазменных сгустков на расстояние от сопла порядка нескольких сантиметров. Плазменный карандаш - это 
ручной плазменно-струйный инструмент, состоящий из двух электродов, каждый из которых выполнен в виде тонкого медного кольца, прикрепленного к поверхности диска из оксида алюминия $\left(\mathrm{Al}_{2} \mathrm{O}_{3}\right)$ или стекла с перфорацией в середине. Оба электрода подключены к высоковольтному импульсному генератору, выдающему импульсы с амплитудой до $10 \mathrm{kV}$, диапазоном варьирования продолжительности импульса от $200 \mathrm{~ns}$ до режима постоянного тока и частотой следования импульсов до $10 \mathrm{kHz}$. Время нарастания и спадания импульса напряжения составляет примерно $60 \mathrm{~ns}$. Обзор областей применения плазменного карандаша представлен в работе [10]. Помимо прочего плазменный карандаш нашел применение в стоматологии [11].

В настоящей работе вместо импульсного источника напряжения постоянного тока использовался источник напряжения переменного тока килогерцевого диапазона, при этом конфигурация электродов была аналогична конструкции электродов плазменного карандаша. Плазменная струя длиной несколько сантиметров генерировалась так же, как и в случае плазменного карандаша. В нашем случае струя холодной плазмы атмосферного давления, генератор которой был назван килогерцевым плазменным карандашом, генерировалась высоким $(18 \mathrm{kV})$ напряжением переменного (синусоидального) тока при частоте $15 \mathrm{kHz}$. Для генерации струи килогерцевого плазменного карандаша использовался поток гелия. В настоящей работе представлены первые результаты определения характеристик килогерцевого плазменного карандаша.

Напряжение переменного тока величиной $18 \mathrm{kV}$ и частотой $15 \mathrm{kHz}$ прикладывается к электродам, аналогичным двум специально разработанным электродам плазменного карандаша, через которые протекает поток гелия. Каждый из двух электродов выполнен в виде тонкого медного кольца, приклеенного жидкокерамическим герметиком (Varian torr-seal) между двумя дисками из оксида алюминия $\left(\mathrm{Al}_{2} \mathrm{O}_{3}\right)$ толщиной $2.46 \mathrm{~mm} \mathrm{c}$ центральной перфорацией. Диаметр медного кольцевого электрода составляет $12 \mathrm{~mm}$, внутренний диаметр диска из $\mathrm{Al}_{2} \mathrm{O}_{3}$ - порядка $5.35 \mathrm{~mm}$, внешний диаметр диска из $\mathrm{Al}_{2} \mathrm{O}_{3}$ - порядка $18.1 \mathrm{~mm}$. Оба электрода прикрепляются к верхней и нижней части цилиндрической диэлектрической кварцевой трубки длиной $10 \mathrm{~mm}$, диаметр которой равен диаметру диска из $\mathrm{Al}_{2} \mathrm{O}_{3}$. Когда верхняя часть диэлектрической кварцевой трубки прикреплена к другой диэлектрической трубке такого же диаметра, струя плазмы выпускается через отверстие внешнего электрода. Схема предлагаемого устройства приведена на рис. 1.

Используемый в качестве рабочего газа гелий (Не, 99.95\%) вводится в диэлектрическую (кварцевую) трубку с регулированием расхода газа в пределах $1-10 \mathrm{~L} / \mathrm{min}$. После того как гелий вводится через верхнюю часть диэлектрической трубки, а на электроды подано высокое напряжение килогерцевой частоты, в промежутке между электродами возникает разряд, и

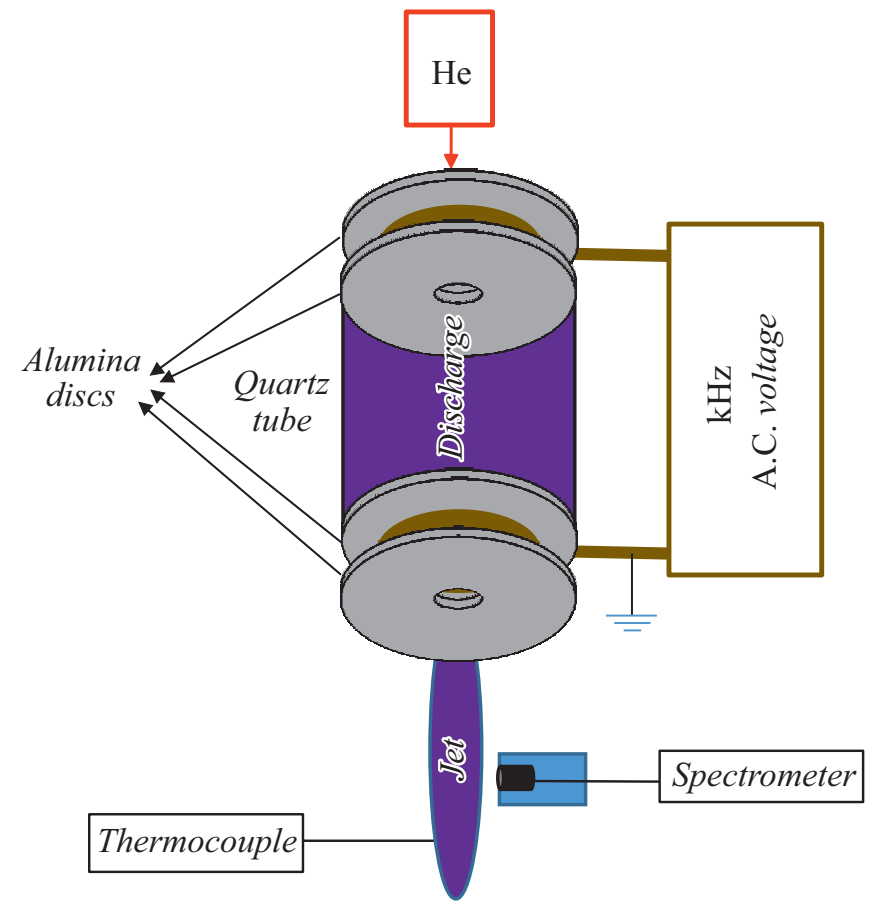

Рис. 1. Схематическое изображение экспериментального образца килогерцевого плазменного карандаша.

через отверстие в нижнем электроде (сопло) в воздух помещения выходит струя плазмы. Видимая длина струи измеряется линейкой, результаты измерений регистрируются цифровой камерой. Длина и форма струи, генерируемой килогерцевым плазменным карандашом, зависит от расхода газообразного гелия. При расходе свыше $7 \mathrm{~L} / \mathrm{min}$ струя существует в диффузном режиме, при этом ее длина увеличивается с увеличением расхода, но при достижении некоторой точки выходит на постоянный уровень. Максимальная длина струи $(30 \mathrm{~mm})$ достигается при расходе газа $10 \mathrm{~L} / \mathrm{min}$ (рис. 2, $b$ ). При расходе свыше $10 \mathrm{~L} / \mathrm{min}$ длина диффузной струи килогерцевого плазменного карандаша становится практически независимой от расхода газа. При расходе газа менее $6 \mathrm{~L} / \mathrm{min}$ струя приобретает неустойчивую изменяющуюся нитевидную форму и при дальнейшем снижении расхода начинает уменьшаться (рис. 2,a). В режиме нитевидной струи ее длина может быть значительно увеличена (до $50 \mathrm{~mm}$ ).

Для измерения температуры струи килогерцевого плазменного карандаша используется стандартная термопара К-типа, подключенная к цифровому мультиметру Fluke 179. Значения температуры струи остаются низкими $\left(28-30^{\circ} \mathrm{C}\right)$, пока термопара располагается на оси на расстоянии $2 \mathrm{~cm}$ от сопла (рис. 1). Измерения температуры повторялись при различных расходах гелия, при этом никаких изменений в данных измерений не наблюдалось. Определенная часть измерений проводилась по прошествии долгого времени после выключения разряда. Это значит, что при длительной эксплуатации прибора 

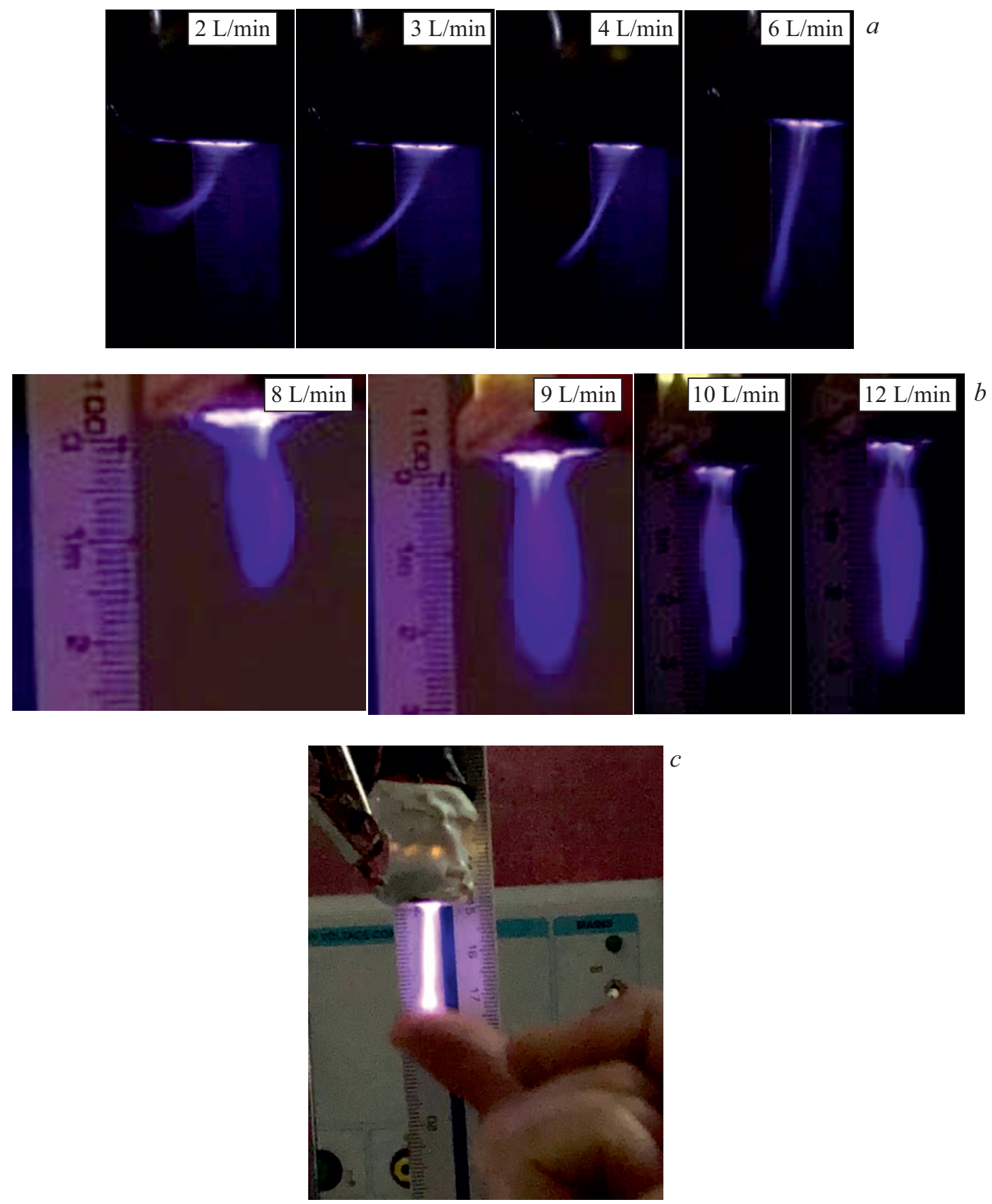

Рис. 2. Фотографии струи гелиевого килогерцевого плазменного карандаша при различных значениях расхода газа. $a-$ режим нитевидной струи килогерцевого плазменного карандаша; $b-$ режим диффузной струи килогерцевого плазменного карандаша; $c$ - обнаженная рука человека (T. Akan) в контакте со струей гелиевого килогерцевого плазменного карандаша.

температура струи не повышается. Однако, если термопара придвигается ближе к соплу (примерно на $1 \mathrm{~cm}$ ), струя рывком сближается с термопарой и образует дугу, при этом температура поднимается до $50^{\circ} \mathrm{C}$. Поэтому для измерения температуры струи использовался также ИК-термометр Benetech GM320. Температура газа оставалась на уровне $22-24^{\circ} \mathrm{C}$, что указывало на низкую температуру струи. К плазменной струе килогерцевого плазменного карандаша можно прикасаться голой рукой, также им можно сканировать кожные покровы человека без образования проводящего следа (рис. 2,c).

Для характеристики факела (струи) килогерцевого плазменного карандаша использовался осевой спектр оптического излучения струи с разрешением $2 \mathrm{~nm}$ в оптическом диапазоне 200-1000 nm. На рис. 3 представлен спектр излучения струи в гелии при напряжении $18 \mathrm{kV}$ с частотой $15 \mathrm{kHz}$ и расходе гелия $10 \mathrm{~L} / \mathrm{min}$. Спектр измерялся мини-спектрометром USB 2000+XR1-ES про- 


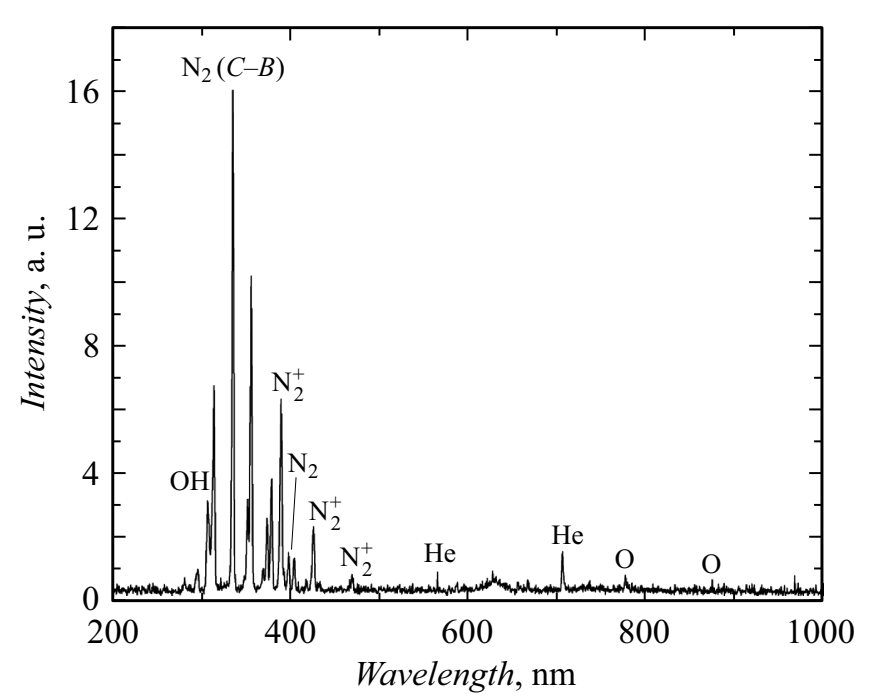

Pис. 3. Спектр излучения струи гелиевого килогерцевого плазменного карандаша в окружающем воздухе.

изводства компании Ocean Optics. Зонд спектрометра из оптического волокна, вставленный в подвижный держатель с отверстием для предотвращения образования электрической дуги со струей, позиционировался примерно в $1 \mathrm{~cm}$ от струи килогерцевого плазменного карандаша; время накопления сигнала устанавливалось равным $100 \mathrm{~ms}$. Спектр оптического излучения измерялся в точке на $1 \mathrm{~cm}$ ниже сопла (нижнего электрода). В спектре наблюдаются очень интенсивные молекулярные линии (колебательные переходы) второй положительной системы $\mathrm{N}_{2}\left(C^{3} \Pi_{u}-B^{3} \Pi_{g}\right)$ (315, 337, $353,357,375,380,399,405 \mathrm{~nm})$, первой отрицательной системы молекулярных ионов $\mathrm{N}_{2}^{+}\left(B^{2} \sum_{u}^{+}-X^{2} \sum_{g}^{+}\right)$ $(391,427,470 \mathrm{~nm})$ и системы гидроксильного радикала ОН $\left(A^{2} \sum^{+}-X^{2} \Pi\right)(309 \mathrm{~nm})$. В спектре излучения доминируют возбужденные состояния $\mathrm{N}_{2}$, а также ионы $\mathrm{N}_{2}^{+}$. Присутствуют также линии атомарного кислорода О $\left(3 p^{5} P-3 s^{5} S^{0}\right.$ и $\left.3 p^{3} P-3 s^{3} S^{0}\right) \quad(777$ и $845 \mathrm{~nm})$. В излучении струи присутствует значительная доля УФ-излучения, относящегося к переходам в полосе $\mathrm{OH}$. Эта полоса появляется в спектре из-за диссоциативного возбуждения молекул воды, присутствующих в воздухе. Прочие наиболее заметные особенности относятся к гелию и располагаются в точках $587 \mathrm{~nm}$ $\left(1 s 3 d^{3} D_{1,2,3}-1 s 2 p^{3} P_{0,1,2}^{0}\right)$ и $728 \mathrm{~nm}\left(1 s 3 s^{1} S_{0}-1 s 2 p^{1} P_{1}^{0}\right)$. Помимо электрического поля и заряженных частиц во взаимодействии плазмы с поверхностью играют значительную роль такие составляющие плазмы, как УФ-излучение, активный кислород и формы азота, особенно во взаимодействии с биологическими клетками и тканями.

Спектры излучения факела плазменного карандаша приведены в работах $[8,12]$. В этом спектре излучения доминируют возбужденный азот, гелий и ионы азота. Кроме того, в спектре были обнаружены такие высокоактивные радикалы, как гидроксил $\mathrm{OH}$ и атомарный кислород. В то время как в спектре излучения факела плазменного карандаша доминируют ионы $\mathrm{N}_{2}^{+}(B-X)$, в спектре излучения струи килогерцевого плазменного карандаша доминируют возбужденные состояния $\mathrm{N}_{2}$ $(C-B)$, как показано на рис. 3. Кроме того, в случае килогерцевого плазменного карандаша УФ-излучение является более интенсивным и происходит при других длинах волн, чем в случае плазменного карандаша. Электронная плотность быстро убывает с увеличением расстояния от сопла благодаря процессам рекомбинации и захвата. Отрицательные и положительные ионы обнаруживаются на более значительных расстояниях от сопла благодаря более низкой скорости рекомбинации. Время жизни возбужденных и активных форм больше, чем у других, поэтому возможно их взаимодействие с материалами на расстояниях до нескольких сантиметров (в зависимости от времени жизни радикалов).

Генераторы АРСРЈ формируют плазменные факелы длиной от нескольких миллиметров до более десяти сантиметров. Динамически плазменные факелы на вид кажутся непрерывными и распространяются с высокой скоростью, напоминая движение пули. В предыдущих публикациях отмечалось, что плазменные факелы, создаваемые генераторами АРСРЈ, управляются в основном электрическими силами. Однако для объяснения кинетики распространения плазменной струи, созданной плазменным карандашом, в условиях слабого электрического поля используется модель на основе процесса фотоионизации [9]. Если вблизи плазменной струи килогерцевого плазменного карандаша (близко, но без непосредственного контакта) помещается заземленная медная пластина, плазменная струя отклоняется в сторону медной пластины и далее не распространяется. Этот факт можно объяснить тем, что плазменный сгусток, создаваемый килогерцевым плазменным карандашом, приводится в движение электрическими силами. Заземленная медная пластина, установленная вблизи плазменной струи, изменяет распределение электрического поля и, следовательно, влияет на процесс распространения плазменной струи.

Был изготовлен прибор, генерирующий плазменную струю атмосферного давления, названный килогерцевым плазменным карандашом по аналогии с уже известным плазменным карандашом, но обладающий отличными от него свойствами. При низких значениях расхода газа килогерцевый плазменный карандаш работает в режиме нитевидной струи, однако при высоких значениях расхода форма струи становится диффузной. Несмотря на общую схожесть со спектром излучения струи плазменного карандаша, в спектре струи килогерцевого плазменного карандаша наблюдается более значительная доля УФ-излучения и более интенсивные линии возбужденных атомов $\mathrm{N}_{2}$. Следует добавить, что килогерцевый плазменный карандаш, как и ранее известный плазменный карандаш, производит плазменные струи комнатной температуры. В модели, предложенной 
для плазменного карандаша, предполагается, что в распространении плазмы важную роль играют локальное электрическое поле и процесс фотоионизации, при этом распространение плазмы замедляется, когда соотношение между молекулами воздуха и атомами гелия превышает определенное значение. Первые результаты исследования действия килогерцевого плазменного карандаша показали, что величина расхода газа не оказывает существенного влияния на длину плазменной струи при работе в диффузном режиме, и есть основания полагать, что распространение плазменной струи происходит под действием электрических сил.

\section{Финансирование работы}

Финансовая поддержка работы осуществлялась в рамках проекта Scientific Research Committee of Eskisehir Osmangazi University (ESOGU-BAP), грант № 201419013.

\section{Конфликт интересов}

Авторы заявляют, что у них нет конфликта интересов.

\section{Список литературы}

[1] M. Laroussi, T. Akan, Plasma Process. Polym., 4, 777 (2007). DOI: 10.1002/ppap.200700066

[2] O.V. Penkov, M. Khadem, W. Lim, D. Kim, J. Coat. Technol. Res., 12, 225 (2015).

DOI: $10.1007 / \mathrm{s} 11998-014-9638-\mathrm{Z}$

[3] S.K. Pankaj, Z. Wan, K.M. Keener, Foods, 7, 4 (2018). DOI: $10.3390 /$ foods 7010004

[4] S.A. Fadhlalmawla, A.H. Mohamed, J.Q.M. Almarashi, T. Boutraa, Plasma Sci. Technol., 21, 105503 (2019). DOI: $10.1088 / 2058-6272 / a b 2 a 3 e$

[5] J. Peran, S.E. Ražić, Textile Res. J., 90, 1174 (2019). DOI: $10.1177 / 0040517519883954$

[6] R. Ma, S. Yu, Y. Tian, K. Wang, C. Sun, X. Li, J. Zhang, K. Chen, J. Fang, Food Bioprocess Technol., 9, 1825 (2016). DOI: $10.1007 / \mathrm{s} 11947-016-1761-7$

[7] X. Lu, M. Laroussi, V. Puech, Plasma Sources Sci. Technol., 21, 034005 (2012). DOI: 10.1088/0963-0252/21/3/034005

[8] M. Laroussi, X. Lu, Appl. Phys. Lett., 87, 113902 (2005). DOI: $10.1063 / 1.2045549$

[9] X. Lu, M. Laroussi, J. Appl. Phys., 100, 063302 (2006). DOI: $10.1063 / 1.2349475$

[10] M. Laroussi, IEEE Trans. Plasma Sci., 43, 703 (2015). DOI: $10.1109 /$ TPS.2015.2403307

[11] A.D. Morris, G.B. McCombs, T. Akan, W. Hynes, M. Laroussi, S.L. Tolle, J. Dental Hygiene, 83, 55 (2009).

[12] N. Mericam-Bourdet, M. Laroussi, A. Begum, E. Karakas, J. Phys. D: Appl. Phys., 42, 055207 (2009).

DOI: $10.1088 / 0022-3727 / 42 / 5 / 055207$ 